\title{
Padrão eletrocardiográfico de ratos após recuperação nutricional
}

\section{Electrocardiographic profile of rats after malnutritional recovery}

\author{
Vitor A Pezolato', André L Mascarin¹, Patrícia C Paulino², Carlos A Silva ${ }^{3}$
}

\begin{abstract}
RESUMO
Modelo do Estudo: Estudo Experimental. Objetivo: A proposta deste estudo foi avaliar se a recuperação nutricional $(\mathrm{RN})$ restaura as alterações metabólicas e elétricas cardíacas deflagradas pela desnutrição. Metodologia: Utilizou-se ratos wistar pós-desmame, divididos nos grupos controle (C, dieta $14 \%$ proteína, 90 dias), desnutridos ( $D$, dieta $6 \%, 45$ dias) e recuperados $(R$, dieta $14 \%$ por 45 dias após a $D$ com dieta 6\%). Foram avaliados o peso corporal (P), o ECG (freqüência cardíaca e intervalos QRS, QTc e PR) e as reservas glicogênicas ventriculares (GLI). Os dados foram submetidos a teste de normalidade e teste de Tukey, $p<0,05$. Resultados: $O$ grupo $D$ apresentou $P$ menor do que $C$, não sendo restaurado com a RN, evento também constatado no GLI. No ECG, o grupo D apresentou valores maiores, indicando sobrecarga cardíaca, os quais foram restabelecidos após a $\mathrm{RN}$, atingindo valores similares ao $\mathrm{C}$. Conclusão: As alterações no músculo cardíaco dos animais $D$ foram revertidas com a recuperação nutricional.
\end{abstract}

Palavras Chave: Eletrocardiografia. Desnutrição. Ratos. Recuperação Nutricional.

\section{Introdução}

A desnutrição proteica é uma condição patológica decorrente das deficiências de substratos energéticos e proteínas atingindo com grande intensidade as crianças. Na literatura científica observa-se que dentre os inúmeros modelos experimentais aplicados ao estudo dos eventos deflagrados pela desnutrição, o modelo de desnutrição crônica precoce, por restrição protéica na ingesta alimentar, é o mais semelhante ao que acontece na população infantil e merecedor de maiores estudos devido à importância social e científica. ${ }^{1,2}$
Todas as células do organismo, em maior ou menor intensidade, sofrem alterações provocadas pela desnutrição protéica, desta forma, quando a desnutrição for imposta precocemente, haverá um grande comprometimento no funcionamento dos órgãos acarretando danos irreparáveis no funcionamento destes. ${ }^{3,4}$

O coração também sofre com os efeitos catabólicos produzidos pela desnutrição, de forma similar ao observado no músculo esquelético. ${ }^{5}$ Conhecidamente sabe-se que as proteínas desempenham papel fundamental para a o equilíbrio estrutural e funcional dos órgãos, assim, a redução na disponibilidade protéica compromete o tecido muscular e o conjuntivo
1. Graduação em Fisioterapia - UNIMEP

2. Bióloga - Faculdade de Ciências da Saúde - UNIMEP

3. Docentes do Programa de Pós-graduação em Fisioterapia UNIMEP
Correspondência Vítor Alexandre Pezolato Duque de Caxias, 47 - Centro CEP 13450-015 - Santa Barbara d'Oeste Vitor.pezolato@gmail.com

Artigo recebido em 21/01/2013 Aprovado para publicação em 02/08/2013 
promovendo um desequilíbrio generalizado, inclusive sendo considerada a desnutrição como um dos fatores indutores de distúrbios cardíacos, com ênfase na arritmia. ${ }^{6}$ Importante ressaltar que, no que se refere a recuperação nutricional, não há consenso, havendo autores que indicam reversão do quadro enquanto outros observaram somente recuperação parcial. ${ }^{7}$

O eletrocardiograma (ECG) é um dos métodos mais importantes no diagnóstico de alterações cardíacas, uma vez que, dependendo da extensão e comprometimento da homeostasia cardíaca observa-se alterações nas ondas e nos respectivos intervalos. As ondas do ECG decorrem da somatória temporal de despolarizações e repolarizações em grupos de fibras cardíacas representando o sinal elétrico no nódulo sinusal, átrios, nódulo atrioventricular, feixe de His, rede de Purkinge e massa ventricular representado pelas ondas P, o complexo QRS e a onda T. ${ }^{8}$

As ondas do ECG permitem distinguir intervalos que correspondem ao tempo para ativar as regiões do coração de forma que a onda $\mathrm{P}$ e seus intervalos correspondem ao tempo desde o início da ativação sinusal ao início da despolarização ventricular. A duração do complexo QRS corresponde ao tempo total para a despolarização ventricular, tem início no feixe de His e dissipa-se pelo tecido condutor His-Purkinge com significativa velocidade na massa ventricular. $\mathrm{O}$ intervalo S-T inicia-se no final do complexo QRS e vai até o início da onda $T$ e corresponde ao tempo que decorre desde o final da despolarização completa até o início da repolarização do ventrículo, ou seja, toda a fase de platô do potencial de ação. O intervalo R-R, que determina o tempo entre duas ondas $\mathrm{R}$ sucessivas, é utilizado rotineiramente para determinar a frequiência cardíaca. Por sua vez, o intervalo entre o início do complexo QRS e o fim da onda T é chamado de intervalo Q-T, e corresponde ao tempo necessário para a completa excitação elétrica e a recuperação dos ventrículos, sendo, portanto, a medida da duração da sístole "elétrica", a qual inclui a despolarização e a repolarização ventricular. ${ }^{9}$

\section{Objetivo}

Baseado nas alterações funcionais descritas na literatura e desencadeadas pela desnutrição protéica, a proposta de trabalho foi avaliar o perfil eletrocardiográfico de ratos desnutridos bem como de ratos recuperados do ponto de vista nutricional.

\section{Material e Métodos}

Foram utilizados 24 ratos Wistar com 21 dias de idade, adquiridos junto à empresa ANILAB $^{\circledR}$ de Paulína/SP. Os ratos foram alojados em gaiolas coletivas contendo no máximo 4 animais e mantidos em sala climatizada $\left(23 \pm 2^{\circ} \mathrm{C}\right)$ com ciclo claro/escuro de $12 / 12 \mathrm{~h}$ recebendo água e ração à vontade. Todos os procedimentos foram autorizados pelo Comitê de Ética em Experimentação Animal da UFScar protocolo 011/2011. Os animais foram aleatoriamente divididos em 3 grupos experimentais denominados Controle $(C$; tratados com dieta AIN 93 M -14\% de proteína durante 90 dias, $n=8)$; desnutridos $(\mathrm{D}$; tratados com dieta AIN 6\% de proteína durante 45 dias, $n=8$ ) e recuperados $(\mathrm{R}$; tratados com dieta AIN 6\% de proteína durante 45 dias e a seguir tratados com dieta AIN $14 \%$ de proteína durante mais 45 dias, n=8) (figura 1). Os grupos tratados receberam dieta adquirida junto a Prag Soluções Biomédicas de Jaú, SP (formulação descrita na tabela 1), sendo o peso corporal acompanhado semanalmente. Após o período experimental, os ratos foram anestesiados com pentobarbital sódico (40mg/Kg, ip) e submetidos à avaliação da atividade elétrica cardíaca (ECG) com o aparelho ECG 98 HEART WARE® (figura 2). Para captação do sinal eletrocardiográfico os eletrodos foram conectados aos canais de um computador (Heart Ware System) e registradas três derivações bipolares (DI, DII e DIII) e nas três derivações amplificadas (aVR, aVL e aVF) com sensibilidade $\mathrm{N}$ e velocidade de $50 \mathrm{~mm} / \mathrm{s}$. O intervalo QT foi medido em dez batimentos consecutivos, do início do complexo QRS ao ponto de retorno da onda T isoelétrica. O intervalo QT foi corrigido pela frequiência cardíaca usando a fórmula de Bazett $(\mathrm{QTc}=\mathrm{QT} /$ "RR). A seguir, amostras do ventrículo esquerdo foram prontamente coletadas e submetidas à avaliação do conteúdo de glicogênio segundo o método do fenol sulfúrico. ${ }^{10}$ Os valores foram expressos em mg/100mg de peso úmido. Na avaliação estatística foi utilizado teste de normalidade Shapiro-Wilk e teste de Tukey, $\mathrm{p}<0,05$.

\section{Resultados}

$\mathrm{Na}$ avaliação do peso corporal foi observado que o grupo desnutrido (tratado com dieta 6\%) apresentou valores $86,4 \%$ menores se comparado ao grupo tratado com a dieta $14 \%$. Por outro lado, o grupo 


\section{Tabela 1}

Composição das dietas adquirida da Prag- Soluções Biomédicas.

Dieta AIN 93 M-14\%

Dieta AIN - 6\% proteína (desnutrição)

\begin{tabular}{lrlr} 
Ingredientes & $\mathbf{p} / \mathbf{1 ~ K g}$ & Ingredientes & $\mathbf{p} / \mathbf{1 ~ K g}$ \\
\hline Amido de milho & 465.700 & Amido de milho & 508.000 \\
Caseína & 140.000 & Caseína & 66.000 \\
Amido dextrinizado & 155.000 & Amido dextrinizado & 166.500 \\
Sacarose & 100.000 & Sacarose & 121.000 \\
Óleo de soja & 40.000 & Óleo de soja & 40.000 \\
Fibra (Cel. Microcrist.) & 50.000 & Fibra (Cel. Microcrist.) & 50.000 \\
L-cistina & 1.800 & L-cistina & 1.000 \\
Cloreto colina & 2.500 & Cloreto colina & 2.500 \\
Mix mineral G & 35.000 & Mix mineral G & 35.000 \\
Mix vitamínico & 10.000 & Mix vitamínico & 10.000 \\
\hline TOTAL & $\mathbf{1 0 0 0 . 0}$ & TOTAL & $\mathbf{1 0 0 0 . 0}$ \\
\hline
\end{tabular}
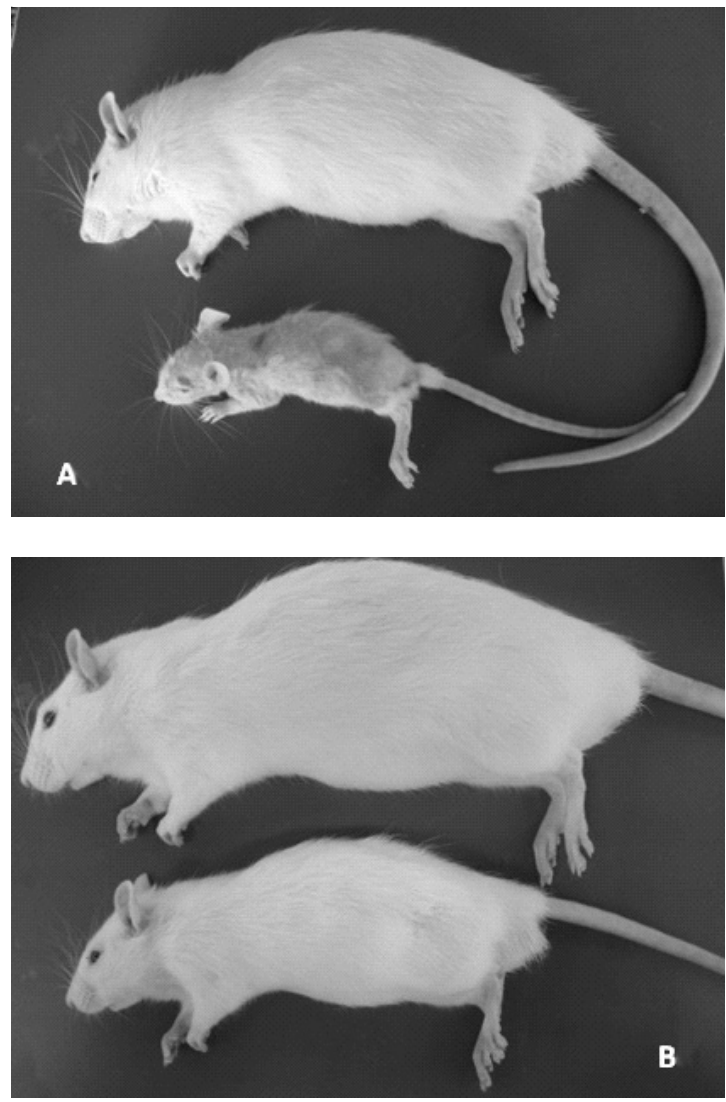

Figura 1. Ratos Wistar nas diferentes fases experimentais. Painel A: ratos com 45 dias tratados com dieta contendo $14 \%$ de proteína (superior) e dieta contendo $6 \%$ de proteína (inferior). Painel B: ratos com 90 dias tratados com dieta contendo $14 \%$ de proteína (superior) e recuperado (tratado com dieta contendo 14\% de proteína após desnutrição). 

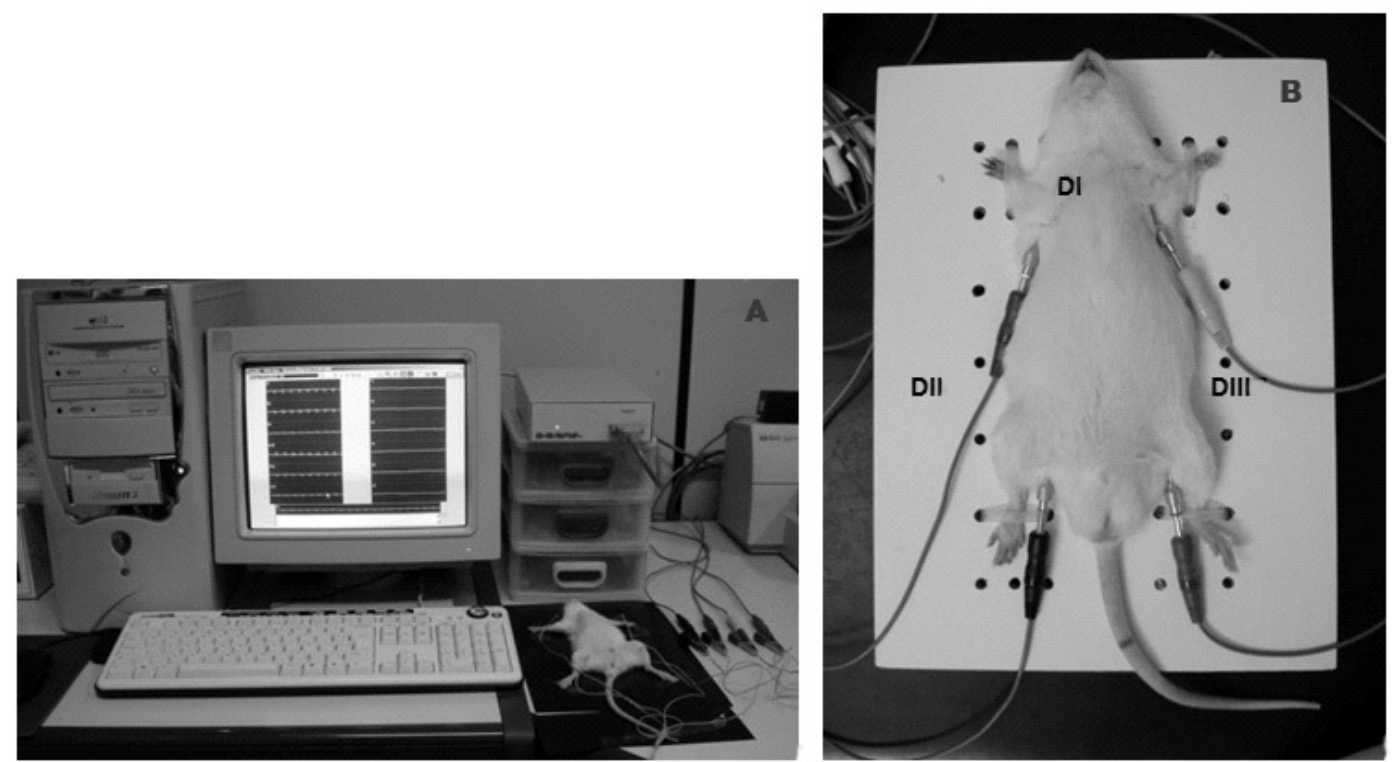

Figura 2. Sistema - Heart Ware 98 usado na captação dos sinais eletrocardiográficos. A) Aparelhagem utilizada para a realização do registro; B) Posicionamento dos eletrodos no corpo do animal.

que foi recuperado apresentou peso $38 \%$ menor que o controle, porém, $355 \%$ maior que o desnutrido como pode ser observado na figura 3.

A seguir foi avaliada a concentração ventricular de glicogênio sendo que o grupo desnutrido apresentou concentrações $73,8 \%$ menores se comparado ao grupo tratado com a dieta $14 \%$. Com relação ao grupo recuperado foi observado que as concentrações foram $130 \%$ maiores se comparado ao grupo desnutrido, no entanto ainda permaneceram $40 \%$ menores do que o grupo tratado com a dieta $14 \%$, como mostra a figura 4.

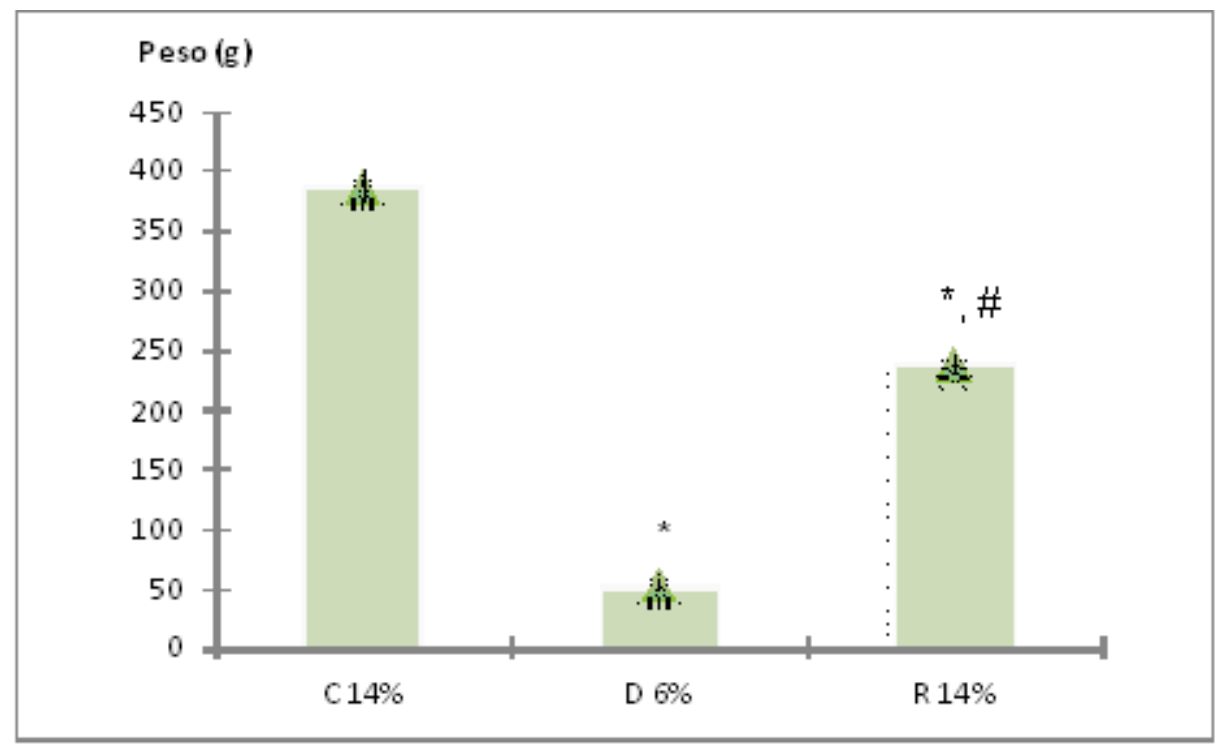

Figura 3. Peso (g) dos animais nas diferentes etapas experimentais. Grupos controle (C; tratado com dieta contendo $14 \%$ de proteína durante 90 dias); Grupo desnutrido ( $D$, tratado com dieta contendo 6\% de proteína durante 45 dias) e Recuperado (R, tratado com dieta contendo $6 \%$ de proteína durante 45 dias e a seguir tratado com dieta contendo $14 \%$ de proteína por mais 45 dias). Valores representam à média \pm epm, $n=20 .{ }^{*} \mathrm{p}<0,05$ comparado ao controle; $\# \mathrm{p}<0,05$ comparado ao desnutrido. 


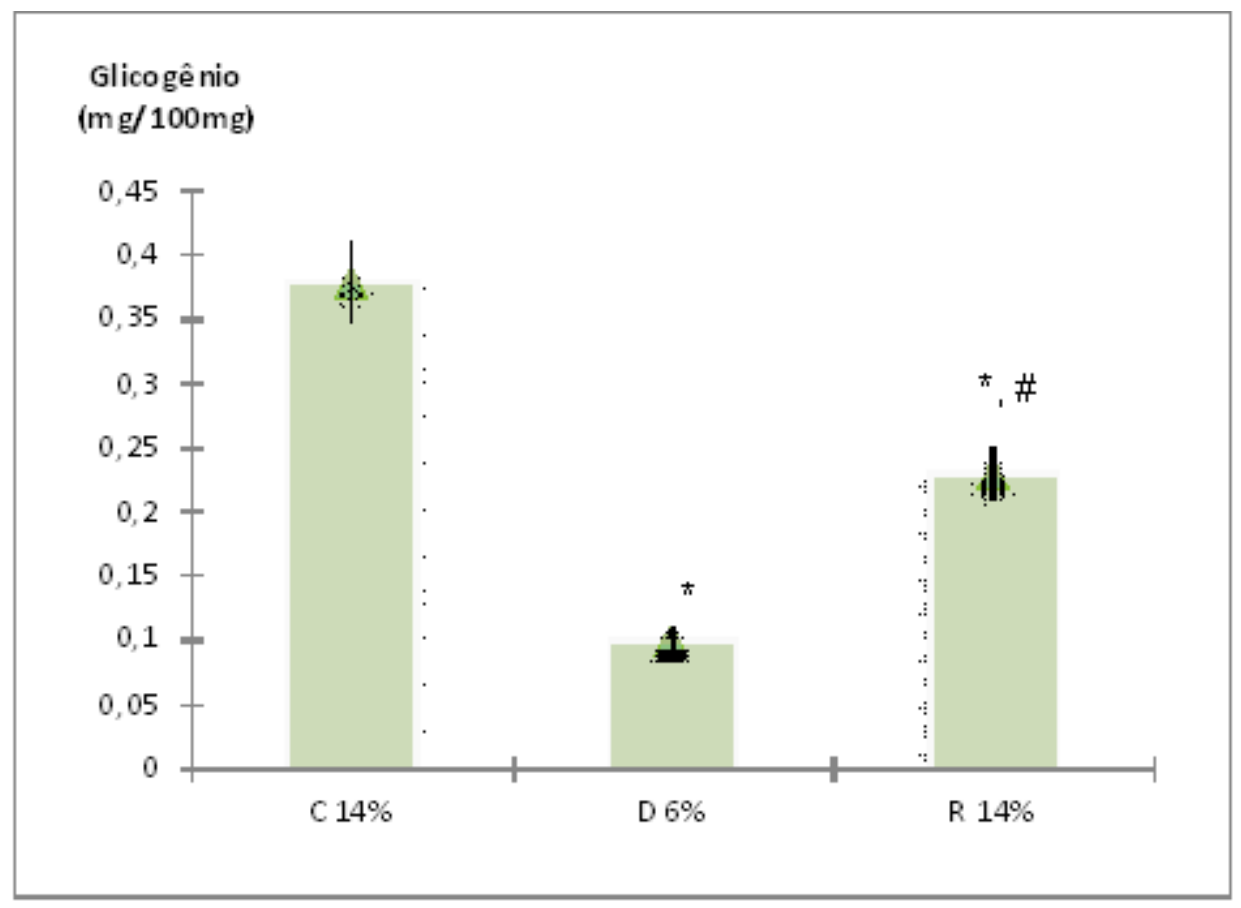

Figura 4. Conteúdo de glicogênio ventricular $(\mathrm{mg} / 100 \mathrm{mg})$ dos animais nas diferentes etapas experimentais. Grupos controle (C; tratado com dieta contendo $14 \%$ de proteína durante 90 dias); Grupo desnutrido (D, tratado com dieta contendo $6 \%$ de proteína durante 45 dias) e Recuperado (R, tratado com dieta contendo $6 \%$ de proteína durante 45 dias e a seguir tratado com dieta contendo $14 \%$ de proteína por mais 45 dias). Valores representam à média \pm epm, $n=20 .{ }^{*} p<0,05$ comparado ao controle; $\# p<0,05$ comparado ao desnutrido.

Dentro da proposta, foi avaliado o perfil eletrocardiográfico dos grupos experimentais sendo observado que a frequiência cardíaca do grupo desnutrido apresentou-se $32 \%$ maior se comparado aos demais grupos, além do que, foram constatadas alterações nas dinâmicas de condução elétrica no grupo desnutrido sendo representado por valores maiores, se comparado ao controle, atingindo $23 \%$ no tempo do intervalo QRS; 79\% no intervalo QTc e 60\% no intervalo PR.
Cabe ressaltar que a mesma avaliação realizada no grupo recuperado pós-desnutrição não mostrou diferença se comparado ao grupo controle, como pode ser observado na tabela 2 .

\section{Discussão}

Diversos pesquisadores ligados a avaliações envolvendo a desnutrição protéica têm utilizado ratos

\section{Tabela 2}

Parâmetros eletrocardiográficos. Freqüência cardíaca (FC, bat/min), complexo QRS (ms) e intervalo QTc (ms) e PR (ms) do eletrocardiograma dos grupos controle (C, dieta 14\%); Desnutrido (dieta 6\%) e Recuperado (dieta $14 \%$ após desnutrição).

\begin{tabular}{lccccccc} 
& FC (bat/min) & QRS $(\mathbf{m s})$ & QTc $(\mathbf{m s})$ & \multicolumn{2}{c}{ PR (ms) } \\
\hline Controle & $157 \quad \pm 12,0$ & $92 \pm 4,6$ & 186,22 & \pm 25 & 34.4 & $\pm 7,8$ \\
Desnutrido & 207 & $\pm 6,8^{*}$ & $113 \pm 2,7^{*}$ & 334,00 & $\pm 40^{*}$ & 86 & $\pm 7,3^{*}$ \\
Recuperado & 198 & $\pm 15,0$ & $83 \pm 1,3$ & 148,00 & \pm 24 & $42 \pm 2,8$ \\
\hline
\end{tabular}

${ }^{*} \mathrm{p}<0,05$ comparado ao controle e ao recuperado. 
devido às similaridades metabólicas com seres humanos. ${ }^{11,12,13}$ Neste sentido, tem sido descrito na literatura que a desnutrição compromete tanto a maturação quanto o equilíbrio homeostático de diferentes sistemas. ${ }^{1,14}$

Quando foi avaliado o peso dos animais desnutridos (tratado com dieta 6\% de proteína), foi observado que este é menor se comparado ao controle e mostra o espectro de ação da desnutrição, uma vez que, por ser uma condição multifatorial pode refletir redução na síntese de hormônios anabólicos (insulina, hormônios tireoidianos, hormônio de crescimento) e catabólicos (corticosterona); modificação no perfil enzimático que limita de maneira generalizada os processos bioquímicos; redução na disponibilidade de aminoácidos e assim, atuando de forma integrada, compromete o desenvolvimento dos órgãos. ${ }^{15,16}$

Outro fator a ser considerado, no que se refere à redução no peso e crescimento dos animais pode ter relação com alterações morfológicas de alguns órgãos envolvidos no processo de absorção e metabolização de substratos, tais como o pâncreas exócrino e o epitélio intestinal e desta forma, comprometer o suprimento de substratos essenciais à síntese proteica tais como os aminoácidos. ${ }^{17,18}$ Reitera-se ainda que, o grupo desnutrido que foi submetido à recuperação nutricional apresentou peso corporal menor do que o grupo controle, porém, encontrava-se em melhores condições se comparado ao grupo desnutrido, indicando a relação direta entre o oferecimento de maior teor de proteína e recuperação do peso corporal. Este estudo corrobora com diversos autores que sugeriram benefícios da reabilitação nutricional. ${ }^{19,20,21,22}$

No que tange as discussões sobre sistemas afetados pela desnutrição sabe-se que o oferecimento de dietas com reduzida porcentagem de proteína afeta significativamente as dinâmicas da insulina, o que promove redução na população de receptores, intolerância à glicose e menor secreção de insulina na presença do secretagogo glicose. ${ }^{23,24}$ Por outro lado, sabe-se que a sensibilidade insulínica retoma a normalidade antecedendo a restauração do sistema secretório da insulina. ${ }^{25,26,27}$

$\mathrm{Na}$ busca de estudos que avaliaram vários aspectos ligados à formação de reservas energéticas em ratos submetidos à restrição protéica, encontramos divergências, havendo diferentes descrições, tais como: redução na captação de glicose no músculo esquelético isolado; elevação na síntese muscular de glicogênio; redução na síntese de glicogênio, enquanto outros au- tores não verificaram diferença significativa. ${ }^{12,28} \mathrm{O}$ estudo em tela acompanha autores que indicam redução na formação das reservas glicogênicas em decorrência da desnutrição, uma vez que, a literatura indica o desenvolvimento do quadro de resistência à insulina, e reitera a reversibilidade parcial das vias de formação das reservas de substratos. ${ }^{24}$

A literatura apresenta trabalhos controversos que mostram que a desnutrição pode melhorar, piorar ou manter inalterada a função miocárdica..$^{29,30,31} \mathrm{Na}$ década de 80 , foram estudados os efeitos da desnutrição sobre o coração sendo verificado tanto redução da massa muscular cardíaca quanto descompensação no equilíbrio homeostático da função cardíaca, evento que foi retratado em um estudo que constatou disfunção diastólica no miocárdio de ratos desnutridos. ${ }^{32,33}$

Tem sido destacado que a desnutrição protéica é a responsável por potencializar condições de bradicardia, redução na ejeção cardíaca, hipotrofia cardíaca. ${ }^{34}$ Neste sentido, um sistema merecedor de destaque está na interface de controle das funções elétricas do marca-passo, onde tem sido destacado aumento na atividade autonômica simpática acompanhando as mudanças fisiológicas e bioquímicas do miocárdio, no intuito de potencializar as necessidades circulatórias, fato que pode intensificar as arritmias. Neste sentido foi relatado aumento no processo de "turnover" de norepinefrina no nódulo sinusal, indicando que a composição da dieta influencia na atividade autonômica simpática. ${ }^{35,36}$ Os resultados aqui apresentados demonstram freqüências cardíacas maiores no grupo desnutrido e corrobora com a sugestão de elevação no domínio adrenérgico no controle do nódulo sinusal.

Demonstramos também a existência de alterações no sistema de condução, acompanhando a dinâmica do nódulo sinusal, aqui representado por alteração no complexo QRS, intervalo QTc e PR. Foi sugerido que a capacidade funcional não é afetada, no entanto, tem sido descrito elevação na intensidade funcional, indicando maior exigência do miocárdio. ${ }^{5} \mathrm{Um}$ importante fator de correlação entre a desnutrição protéica e a função cardíaca se relaciona ao acúmulo do colágeno no músculo cardíaco, comprometendo a dinâmica de propagação de sinais elétricos e possivelmente ter relação com as alterações eletrocardiográficas observadas neste estudo.

Um ponto de destaque se refere à condição morfológica dos cardiomiócitos obtidos de humanos adultos desnutridos que foram necropsiados onde foi constatado menor espessura no músculo cardíaco in- 
dicando hipotrofia. ${ }^{37}$ Acompanhamos estes resultados acrescentando que este é um fator extremamente importante para manutenção das condições de normalidade da condução elétrica e pode reforçar as alterações elétricas constatadas.

$\mathrm{Na}$ análise realizada nos animais submetidos à recuperação nutricional foi verificado uma expressiva melhora nos padrões energéticos e elétricos cardíacos indicando o potencial recuperativo das funções, e se deve a preservação de componentes estruturais do coração os quais são essenciais para a homeostasia metabólica e funcional. ${ }^{37}$ Indicando que o coração é um órgão privilegiado e passível de remodelação de suas funções desde que a disponibilidade de substratos energéticos seja recomposta.

\section{Conclusão}

O estudo mostra que as alterações eletrocardiográficas e metabólicas deflagradas no músculo cardíaco, frente à desnutrição proteica, apresentam reversibilidade concomitante com a recuperação nutricional.

\section{Agradecimento}

FAPESP - processo 2010/50950-7

\begin{abstract}
Study Model: Experimental study. Objective: The purpose of this study was to evaluate if the nutritional recovery (NR) restores the metabolic and electrical cardiac changes induced by protein malnutrition. Methods: We used Wistar rats after weaning that were divided into control group (C, 14\% diet protein, 90 days), malnourished ( $M, 6 \%$ diet protein, 45 days) and recovered ( $R, 14 \%$ diet protein for 45 days after $D)$. We evaluated the body weight (BW), ECG (heart rate and QRS intervals, QTC and PR) and ventricular glycogen reserves $(G L Y)$. The data were submitted to normality tests and Tukey's test, $p<0.05$. Results: Group M showed lowers weight than C, and don't restored with the RN, the event also found in GLY. In ECG, group $M$ showed higher values, indicating cardiac overload, which were restored after nutritional recovery, reaching similar values to $C$. Conclusion: Changes in cardiac muscle of $M$ animals were reversed with nutritional rehabilitation.
\end{abstract}

Keywords: Electrocardiography. Malnutrition. Rats. Nutrition Rehabilitation.

\section{Referências Bibliográficas}

1. Nunes ML, Batista BB, Micheli F, Batistella V. Effects of early malnutrition and nutritional rehabilitation in rats. J Pediatr. 2002; 78:39-44.

2. Abalan F, Mayo W, Simon H, Le-moal M. Paradoxical effect of severe dietary restriction on Long-Evans rat life span. Int $\mathbf{J}$ Vitam Nutr Res.2010; 80:386-93.

3. Feliciano EAO, Oliveira LM, Souza DG. Aquisição e reversão de discriminações em ratos desnutridos. Braz J Behav. 2007; Anal. 3: 79 -95.

4. Xi P, Jiang Z, Zheng C, Lin Y, Wu G. Regulation of protein metabolism by glutamine: implications for nutrition and health. Front Biosci. 2011; 1: 578-97.

5. Drott C, Lundhome K. Cardiac effects of caloric restriction mechanisms and potential hazards. Int $\mathbf{J}$ Obes Relat Metab Disord. 1992; 16: 481-6.

6. Spanheimer R, Zlatev T, Umpierrez G, DiGirolamo M. Collagen production in fasted and food-restricted rats: response to duration and severity of food deprivation. J Nutr. 1991; 121: 518-24.

7. Silva MP, Stevanato E, Moreira VM, Porto M, Mello MAR. Efeito da desnutrição e recuperação nutricional sobre respostas metabólicas e ao exercício crônico em ratos Jovens. Motriz Rev Educ Fís. 1999; 5: 152-9.
8. Tanaka, Y, Shimizu F, Nozuchi S, Yamazaki Y, Nakasone A Interpretation of ECG " The transient analysis of abnormal electrocardiogram. MASUI. 2010; 59: 127-39.

9. Schwarz L. Eletrocardiografia. Revista Ilha Digital. 2009; 1: 3-19.

10. Siu LO, Russeau JC, Taylor AW. Determination of glycogen in small tissue samples. J Appl Physiol. 1970; 28: 234-236.

11. Gopalan, S. Malnutrition: causes, consequences, and solutions. Nutrition. 2000; 16: 7-8.

12. Guzmán-silva MA, Wanderley AR, Macedo VM, Boaventura TG. Recuperação da desnutrição em ratos mediante rações adicionadas ou não de suplemento alimentar e de vitaminas e minerais durante o período de crescimento. Rev. Nutr. 2004; 17: 13-22.

13. Sanches EF. Efeito da desnutrição proteica em ratos submetidos hipóxia isquêmica neonatal. Dissertação de Mestrado, UFRG. 2010: p. 111.

14. Escriva F, Kergoat M, Bailbé D, Pascual-leone AM, Portha, B. Increased insulin action in the rat after protein malnutrition early in life. Diabetologia. 1991; 34: 559-564.

15. Gobatto CA. Alterações metabólicas decorrentes do treinamento físico em ratos previamente desnutridos e recuperados. [Dissertação de Mestrado]. UNICAMP, Campinas, 1993. 
16. Torum B, Chew F. Protein energy malnutrition. In. Shils M, Olson JA, Shike M (eds). Modern Nutrition in Health and Disease. 2: Lea \& Febiger: Philadelphia. 1994: 950-76.

17. Campos D.G, Madi K. Studies on pre- and post-natal malnutrition in albino rats. Partial ponderal and biochemic recuperation. Rev Bras Pesqui Méd Biol. 1975; 8: 301-6.

.18. Millward DJ. Protein deficiency, starvation and protein metabolism. Proc Nutr Soc. 1979; 38: 77-88.

19. Sharma SK, Behari M, Maheshwari MC, Selvamurthy W. Seizure susceptibility \& intrarectal sodium valproate induced recovery in developing undernourished rats. Indian $\mathbf{J}$ Med Res. 1990; 92: 120-7.

20. Sharma SK, Selvamurthy W, Maheshwari MC, Singh TP. Kainic Acid induced epileptogenesis in developing normal 7 undernourished rats. Indian J Med Res. 1990; 92: 456-66.

21. Galdino R, Mello MAR, Almeida RL, Almeida CCS. Desnutrição protéico-calórica. In: Dâmaso A, editor. Nutrição e exercício na prevenção de doenças. Rio de Janeiro, RJ: MEDSI. 2001; 10: $255-75$.

22. Oliveira EL, Cardoso L M, Pedrosa ML, Silva ME, Dun NJ, Colombari E, Moraes MFD, Chianca DA. A low protein diet causes an increase in the basal levels and variability of mean arterial pressure and heart rate in Fisher rats. Nutr Neurosci. 2004; 7: 201-5.

23. Latorraca MQ, Carneiro EM, Mello MAR, Boschero AC. Reduced insulin secretion in response to nutrients in islets from malnourished young rats is associated with a diminished calcium uptake. J Nutr. 1999; 10: 37-43.

24. Soliman AT, Elzalabany MM, Salama M, Ansari BM. Serum leptin concentrations during severe protein-energy malnutrition: correlation with growth parameters and endocrine function. Metab. 2000; 49: 819-25.

25. Crace CJ, Swenne I, Khon PG, Strain J, Milner RDG. Protein energy malnutrition induces changes in insulin sensitivity. Diabetes Metab. 1995; 16: 484-91.

26. Mello MAR. Desnutrição proteico calórica, gravidez e desenvolvimento materno. Estudo comparativo de alterações corporais e metabólicas entre ratas jovens e adultas. Tese de doutorado, ICB, USP, 1995.
27. Neiva CM, Guerino MR, Mello MAR. análise dos efeitos da desnutrição proteico-calórica sobre as respostas ao exercício agudo (single section) parâmetros metabólicos. Motriz Rev Educ Fís. 1999; 1: 32-43.

28. Nolte LA, Galuska D, Martin IK, Zierath JR, Wallberghenriksson, $H$. Elevated free fatty acid levels inhibit glucose phosphorylation in slow-twitch rat skeletal muscle. Acta Physiol Scand. 1994; 151: 51-9.

29. Klebanov S, Herlihy JT, Freeman GL. Effect of long-term food restriction on cardiac mechanics. Am J Physiol. 1997; 273: 2333-42.

30. Nutter DO, Murray TG, Heymsfield SB, Fuller EO. The effect of chronic protein-calorie undernutrition in the rat on myocardial function and cardiac function. Circ Res. 1979; 45: 14452.

31. Bing OHL, Fanburg BL - The influence of dietary protein deficiency on the performance of isolated muscle preparations from the rat left ventricle. Am J Med Sci. 1985; 229: 192-5.

32. Okoshi MP, Dal Pai V, Meyer MM, Silva M, Cicogna AC. Morphological alterations in heart muscle tissue from undernourished hypertensive rats. J Am Coll Cardiol. 1998; 31 : 331-8.

33. Fioretto JR. Estudo funcional, morfométrico e bioquímico do coração isolado de ratos jovens submetidos à desnutrição energético-protéica desde o nascimento. Tese de doutorado, Faculdade de Medicina, Botucatu, SP, 1999.

34. Martins CD, Chianca DA, Fernandes LG. Cardiac autonomic balance in rats submitted to protein restriction after weaning. Clin Exp Pharmacol Physiol. 2011; 38: 89-93.

35. Young JB, Kaufman LN, Saville ME, Ladsberg L. Increased sympathetic nervous system activity in rats fed a low protein diet. Am J Physiol. 1985; 248: 627-637.

36. 1. Oliveira JC, Silva APS, Barbosa FB. Avaliação da evolução ponderal e homeostasia glicídica de ratos submetidos à desnutrição protéica lactacional. Mossoró: Universidade do Estado do Rio Grande do Norte. Expressão; 2003; 34: 53-60.

37. Cunha PF, Pedrini CH, Souza JC, Reis MA, Ramos SG, Cunha SF. Myocardial morphometry of protein-energy malnourished adults. Arq Bras Cardiol. 1998; 71: 677-80. 